\title{
Representações do eleitor: revendo teorias e propondo novos caminhos
}

\author{
Denise Franca Barros \\ Ebape/FGV-RJ \\ João Felipe Rammelt Sauerbronn \\ FGV Direito Rio \\ Eduardo André Teixeira Ayrosa \\ Ebape/FGV-RJ
}

\begin{abstract}
Em virtude da restrita produção acadêmica sobre comportamento do eleitor e marketing político na administração pública, acreditamos que a sistematização do conhecimento produzido na área possa ser capaz de mostrar um amplo campo de possibilidades para futuros estudos críticos, teóricos e empíricos. Observamos que a maior parte das pesquisas acompanha a orientação tradicional, dominante no marketing gerencial. Esses estudos partem do pressuposto de que o marketing político é uma ferramenta utilizada para influenciar o eleitor e que a escolha política é uma decisão eminentemente racional. Assim, o marketing político é normalmente tratado como uma subárea do marketing e, acompanhando a visão dominante dessa disciplina, é visto como essencialmente utilitário. Desta forma, se o candidato é encarado como um produto, seria possível mudar seu "composto de marketing" para "reposicioná-lo". Entendemos que esses pressupostos não só diminuem a importância política do processo e subestimam as capacidades tanto do eleitor quanto do político, como também superestimam a importância da propaganda política. Uma alternativa a essa visão passa pela compreensão da incapacidade de separar razão e emoção durante o processo de formação de preferências do indivíduo. Este artigo tem por objetivo realizar uma breve revisão teórica dos estudos do comportamento do eleitor, apontando outras perspectivas possíveis para o desenvolvimento da pesquisa na área.
\end{abstract}

Palavras-chave: comportamento do eleitor; marketing político; voto; marketing eleitoral; administração pública.

Representing the voter: reviewing the literature and proposing a new theoretical approach Due the restricted academic production on voter behavior and political marketing in the public administration area, we believe that the systematization of knowledge produced can show a wide variety of

Artigo recebido em mar. 2011 e aceito em jul. 2011.

RAP - Rio de Janeiro 46(2):477-91, mar./abr. 2012 
possibilities for critical, theoretical and empirical studies. Most research in voter behavior and political marketing follows an orientation aligned with the dominant paradigm in marketing management studies. These studies assume that political marketing is an instrument useful to influence the voter, and that political choice is a fundamentally rational decision. Thus, political marketing is usually treated as a sub-area of marketing, following the dominant vision of this discipline. If the candidate is treated as a product, it would be, therefore, possible to change its "marketing mix" and its "positioning". We understand that those assumptions not only reduce the political importance of the process and underestimate the capabilities of the voter as well as the politician, but also overestimate the importance of the political advertising. An alternative approach to voter behavior proposes that reason cannot be completely disconnected from emotion during the process of individual preference formation. The aim of this article is to present a brief theoretical revision of the studies of the voter behavior, and propose other possible perspectives that could contribute to the development of research in the area.

KEY WORDS: voter behavior; political marketing; vote; electoral marketing; public administration.

\section{Introdução}

Diferentes áreas do conhecimento, em especial as ciências sociais e políticas, realizaram esforços no sentido de conhecer o eleitor, suas escolhas e dinâmica de comportamento político (Praça, 2005). Entender como o cidadão faz suas escolhas políticas constitui fator central de interesse não só em pesquisas de ciências sociais e políticas, como também na administração pública e no marketing político (O’Shaugnnessy, 2001; Baines e Egan, 2001). No entanto, a produção brasileira ainda é pouco representativa e o eleitor brasileiro subestudado, especialmente no âmbito da administração.

A perspectiva tradicional dos estudos é consistente com a orientação gerencial do marketing para produtos e parte das seguintes premissas: 1) o eleitor ocupa uma posição de "sub-racionalidade", sendo facilmente manipulável pelas campanhas políticas; as campanhas podem determinar o resultado de uma eleição; e 2) o político é encarado como um produto que pode ter sua embalagem e seu conteúdo mudados a qualquer momento para ser reposicionado, diminuindo assim a importância do próprio processo político.

O objetivo deste artigo é fazer um levantamento do que vem sendo produzido sobre o comportamento do eleitor. Ao evidenciar que podem existir outros olhares sobre o tema além da influência de fatores externos no comportamento, intentamos também questionar a afirmação de que uma escolha, qualquer que seja, possa excluir as emoções para ser a "certa". Em virtude da pequena produção sobre comportamento do eleitor e marketing político na administração pública, acreditamos que a sistematização do conhecimento produzido na área possa ser capaz de mostrar o enorme campo de possibilidades que se apresenta. Pensamos que a administração pública, em especial o marketing, tem muito a oferecer para este campo de estudo e que a pluralidade de visões só poderá trazer benefícios para a compreensão maior do tema.

A seguir apresentaremos um referencial teórico que contém breve histórico da origem da utilização do marketing político no Brasil para depois analisarmos a relação existente entre 
marketing político e de empresas e realizarmos uma breve explanação sobre o marketing político e eleitoral. Esses conceitos são importantes para chegarmos ao nosso verdadeiro objeto de interesse: o comportamento do eleitor e sua relação com o voto. Pensamos que os estudos existentes não estão focados na dimensão do eleitor e em sua relação com o voto. Ao humanizar a discussão, estudando o comportamento do eleitor através de como ele constrói a ideia de votar, acreditamos preencher uma lacuna ainda aberta na compreensão do comportamento do eleitor.

\section{Referencial teórico}

O uso de ferramentas e conceitos de marketing político no Brasil não é recente, embora a própria prática democrática o seja. Ainda nas décadas de 1940, 1950 e 1960, alguns conceitos de marketing político já eram utilizados em campanhas de imagem ou eleitorais como a de Getúlio Vargas (criação da alcunha "pai dos pobres", construída pelo Departamento de Imprensa e Propaganda — DIP — do governo estadonovista), Jânio Quadros (com o tema da vassourinha da corrupção), Jango (a imagem de "presidente bossa nova") (Queiroz, 1998).

Cada um dos temas citados acima tinha um objetivo claro. A imagem de pai dos pobres associava Getúlio Vargas à proteção e fortaleza que as camadas mais baixas da população esperavam em um momento histórico onde o Estado desenvolvimentista precisava do apoio dos trabalhadores para a consecução de seus objetivos de industrialização. Já a imagem de presidente bossa nova, assumida por João Goulart, explicitava a modernidade que se pretendia imprimir nos rumos da política nacional.

Mas é importante lembrar que essa utilização é essencialmente de ordem prática, instrumental. O marketing político normalmente é visto apenas como técnica para formular uma campanha, como forma de maximizar os recursos para garantir o acesso ao poder ou para nele se manter. Nos anos pós-ditadura militar, com a abertura democrática e a realização de eleições diretas, cresceu a importância desta visão utilitarista do marketing político, embora a pesquisa acadêmica nacional não tenha acompanhado este crescimento.

Esta ausência se faz notar em especial em congressos da área de administração e na literatura de marketing. As exceções encontram-se em pesquisas e congressos de comunicação social e das ciências sociais e políticas, cuja grande maioria dos trabalhos foca o evento eleitoral (o comportamento social em uma determinada eleição ou em uma série de pleitos) ou a influência da mídia e das campanhas políticas no comportamento dos indivíduos na eleição. Esse tipo de visão certamente é importante porque busca relações de causalidade entre fatores e estuda o comportamento do eleitor com base nos fatores externos que o influenciam. Contudo, acreditamos que ainda existe uma lacuna a ser preenchida, o estudo de como o eleitor constrói a ideia de voto e sua relação com ele, qual sua lógica, suas razões e as emoções envolvidas.

$\mathrm{Na}$ literatura internacional encontra-se maior número e diversidade de trabalhos publicados, seja tanto em periódicos de marketing, quanto de sociologia e de políticas públicas. 
Publicações europeias e americanas como o Journal of Public Affairs, Journal of Marketing Management, Public Opinion Quartely, Advances in Consumer Research e European Journal of Marketing constantemente apresentam em suas edições trabalhos sobre marketing político e comportamento do eleitor, embora não com o mesmo peso e relevância dos estudos de marketing de produtos e serviços.

A pesquisa acadêmica internacional focaliza não só aspectos utilitários do marketing político através da utilização de ferramentas do marketing tradicional (Niffenegger, 1989), como também existem estudos teóricos que aplicam teorias comportamentais e políticas no estudo do comportamento do eleitor, na análise do evento eleição como um ritual e o uso de analogias militares em campanhas (Marland, 2003). Há também os que buscam uma teoria específica do marketing político (Wring, 1997), como também aqueles que buscam evidenciar e comparar as semelhanças e diferenças entre o marketing tradicional e o político (Kotler, 1975; Shama, 1975; Lock e Harris, 1996).

\section{1. Relação entre o marketing político e de empresas}

Na literatura brasileira encontram-se vários exemplos da abordagem instrumental do marketing político: livros elaborados por criadores de campanhas presidenciais e "marqueteiros" envolvidos com a criação de imagem de candidatos. Segundo essa visão, a linguagem corrente usada em campanhas eleitorais é uma evidência da origem comercial do marketing político. O candidato seria considerado um produto e a campanha política, o esforço coordenado para vendê-lo.

Essa maneira de encarar o marketing político como algo fundamentalmente utilitário é consistente com a forma como o próprio marketing é visto pelos praticantes fora da arena política. A visão utilitarista é compatível com a orientação fortemente gerencial formada pelos autores em marketing. Não é de se espantar que a maior parte dos manuais de marketing político seja feita por publicitários formados em comunicação de produtos, capazes de vender o político como produto.

A comparação entre o marketing comercial e o político pode ser útil, mas não passa de uma forma de identificar as características comuns e as diferenças. Sua utilidade reside no fato de que a comparação entre a compra de um produto e a "compra do produto político" impõe ao candidato uma postura ativa de persuasão de eleitores que podem ser "arrebanhados" apenas através de seu esforço de convencimento.

O ponto crítico dessas diferenças localiza-se no lado do "comprador", o eleitor, já que, mesmo encarado como tal, ele é um comprador diferente do consumidor comercial. A insistência em desconhecer ou ignorar estas diferenças e o hábito de tratar o eleitor como se fosse um consumidor de produto comercial são dos aspectos que remetem à visão utilitarista do marketing político. Desta perspectiva, a estratégia política seria subordinada à estratégia de vendas, o que certamente pode trazer efeitos graves para a administração pública, a formação das agendas políticas e o desenvolvimento de políticas públicas. 
O marketing político é normalmente tratado como uma subárea do marketing e, acompanhando a visão dominante desta disciplina, é visto como essencialmente utilitário. Conforme notamos, é corrente a comparação entre o ato de comprar e o ato de votar. Mas essa analogia pode esconder algumas diferenças mais explicativas do que as semelhanças que existem entre o marketing comercial e o político. O marketing político é sistematicamente comparado com o marketing comercial, seja através de seus conceitos e ferramentas, seja por meio dos modelos de comportamento do consumidor (Kotler, 1975; Shama, 1975; Lock e Harris, 1996; Marland, 2003; Bannon, 2003).

De fato, o político pode ser visto como um prestador que oferece seus serviços para a população que o elegeu, embora ele deva servir igualmente a quem não votou nele. A eleição é o momento da aquisição, onde cada eleitor/consumidor possui o mesmo poder de compra sob a forma de voto único (Marland, 2003).

O momento da "compra" é que difere: um produto ou serviço normalmente pode ser adquirido em diversos locais e horários, de acordo com a conveniência do consumidor, mas a eleição acontece em data única, em locais predefinidos, sem a interferência do indivíduo (Lock e Harris, 1996). E mais, é remota a possibilidade de devolução do "produto", caso o "consumidor" se arrependa. Um exemplo disso pode ser o caso Fernando Collor de Mello. Collor se elegeu presidente com uma plataforma populista de "caça aos marajás", com amplo apoio das camadas mais baixas da população e meses depois de eleito sofreu um processo de impeachment que resultou na cassação de seu mandato. Esse fato pode ter gerado sentimentos que poderão ser levados em consideração em decisões políticas futuras. Não só pelo medo do arrependimento, como também pela vergonha de se ter votado em alguém que se descobriu envolvido em escândalos.

Trabalhos como os de Lock e Harris (1996), Dean e Croft (2001) e O'Shaugnnessy (2001) discordam de autores como Kotler, que vê os contextos político e comercial como essencialmente semelhantes. Para O’Shaugnnessy (2001:1047), o marketing é: "uma disciplina de negócios cuja relevância se encontra primeiramente nos negócios: nós não devemos supor que os contextos políticos são invariavelmente análogos aos negócios até o ponto em que os métodos podem ser importados e usado com igual efeito".

O autor critica a visão prescritiva do marketing político e diz que, se os contextos são diferentes, nem sempre a aplicabilidade de modelos e ferramentas do marketing convencional é integral. Apesar disso, ele reconhece alguns paralelos entre a venda de certos produtos e a "venda" de políticos, já que eles vendem um determinado nível de promessa futura, um produto que é abstrato e intangível, uma visão destinada a atrair pessoas cuja realização se dará em um prazo vago e incerto.

Outra diferença que deve ser observada é que o consumidor pode comprar. É um direito. No Brasil, o eleitor deve votar. Mesmo que inutilize seu voto, o comparecimento às urnas é obrigatório. É um dever constitucional aplicado a todos os cidadãos brasileiros acima de 18 anos, independente de sua raça, cor ou credo, passível inclusive de punições e sanções. Neste sentido, o ato de votar pode ser comparado a qualquer ato condicionado de profilaxia, como escovar os dentes ou vacinar-se. 
Dermody e Scullion (2001) também possuem uma visão crítica, mas alinhada com a perspectiva pós-moderna, apontando que as perspectivas tradicionais sobre a contribuição do marketing para a política partem da visão gerencial, em que o comportamento e a oferta política se encontram restritos ao processo de troca.

Wring (1997) aponta que a importância do consumo na criação de significado nas vidas dos indivíduos é central no pensamento de marketing moderno. Assim, para entender o comportamento do eleitor, é necessário, antes, conhecer o consumo político e o(s) significado(s) atribuído(s) a ele.

Se, ao escolhermos um candidato, estamos escolhendo um entre vários existentes, retornamos à comparação com a escolha de uma marca de um produto qualquer entre várias no mercado. A decisão envolve duas esferas que podem influenciar o processo em maior ou menor grau, a racional e a emocional (Lazarus, 1982). Comumente utilizada pelos pesquisadores da área, a figura do "homem-computador" é empregada para explicar como o fenômeno emocional interfere no processo de tomada de decisão do indivíduo. Estendendo tal visão ao estudo do comportamento do eleitor, a formação de preferências e as escolhas são vistas como uma série de decisões racionais que se iniciam com o processamento de informações que possibilitam a escolha de um "produto" e se transformam em decisões "de compra" (Holbrook e O'Shaughnessy, 1984).

Nos diferentes estágios, as emoções podem influenciar o processo de escolha e até mesmo determiná-lo. Afinal, é complexa a tarefa de escolher um candidato, na medida em que são associados a ela sentimentos como responsabilidade, antecipação dos eventos futuros que podem ser cruciais na vida cotidiana e o próprio medo do arrependimento (Marland, 2003; Niffenegger, 1989). O estudo das emoções no comportamento do eleitor ainda carece de maior aprofundamento, mas já existem evidências de sua influência, conforme apontado por Zajonc (1980) na sua pesquisa sobre a formação de preferências.

\subsection{Marketing político e eleitoral: definições e objeto}

Baines e Egan (2001) afirmam que o marketing político é relativamente novo em termos históricos, mas existem exemplos de campanhas políticas anteriores à era cristã. Os mais antigos incluem as eleições e as posições conquistadas para tribunas militares por Tiberius e mais tarde, seu irmão mais jovem, Caius Gracchus no século II a.C., na Roma Antiga.

Wring (1997:653) concebe marketing político como: "o uso do partido ou do candidato de pesquisa de opinião e análise do ambiente para produzir e promover uma oferta competitiva que ajudará a realizar objetivos organizacionais e satisfazer grupos de eleitores em troca dos seus votos".

A mesma autora aponta os componentes do marketing político moderno: a existência de um eleitorado de massa; competição entre dois ou mais partidos para os votos deste eleitorado; e uma série de regras que governam essa competição. Sua conclusão é que a principal relação dentro do mercado político é baseada no conceito central da teoria de marketing: a 
troca entre o comprador e o vendedor. Assim, os cidadãos dão seus votos aos políticos em troca da promessa de ter seus interesses defendidos e promovidos, corroborando com a analogia da venda.

Na literatura nacional, as definições parecem acompanhar a visão utilitarista, focando a eleição ou como mobilizar e influenciar indivíduos para o evento, simplificando o valor do voto e, consequentemente, de sua construção. Pacheco (1993) diz que na expressão marketing político o substantivo é marketing e político é o adjetivo. Segundo o autor, o crescimento do papel do marketing nas eleições é tamanho que:

hoje é simplesmente inimaginável uma eleição puramente política, sem contribuição substancial do marketing. (...) A ideia central nesse constructo é que política e eleição são processos diferentes entre si. Imbricam-se, mas não se confundem. Se, naquele, "o primado é do político", neste "o primado é do eleitor", essa grande massa desinteressada - ou melhor — indiferente à política. Por isso, tenho afirmado que a operacionalização do processo eleitoral consiste, em última análise, na "administração da indiferença", ou seja: trata-se de um processo predominantemente mercadológico porque essencialmente oligopolitizado. (Pacheco, 1993:18)

Grandi, Marins e Falcão (1992) diferenciam o marketing político do eleitoral em função do tempo. Marketing político estaria relacionado à construção de uma imagem a longo prazo, que poderia ser utilizada por qualquer pessoa que deseje projeção pública. Já o marketing eleitoral foca o evento eleitoral. Trata-se de estratégia e tática de curto prazo para que na eleição o candidato receba o maior número de votos, cumprindo o objetivo de se eleger.

A concepção utilitarista do marketing político parece perpassar a literatura brasileira na medida em que define mercado eleitoral como uma relação entre a oferta de um ou mais candidatos e a demanda, com o eleitor. Assim, os esforços para conhecê-lo fazem parte de uma estratégia. Outra evidência da natureza instrumental do marketing político diz respeito à concepção de objeto da disciplina. Pacheco (1993:13) afirma que "é o eleitor indefinido, indeciso ou neutro - o indiferente à política — que constitui a maioria esmagadora do eleitorado. (...) Trabalhamos sobre o eleitor e não sobre o voto. O voto é uma decorrência da posição do eleitor". Esta declaração demonstra que o foco tradicional é a influência sobre o eleitor e não a compreensão de seu comportamento.

A ciência política parece se afastar um pouco da redução do marketing político como propaganda na medida em que o define como:

a utilização de princípios do marketing na atividade política, seja ela de governos, partidos ou personalidades políticas, estando em imediato processo eleitoral ou não. (...) Daí a necessidade de se trabalhar com o conceito e a prática do marketing político-eleitoral e não com o de "comunicação política" ou "propaganda política", "publicidade" ou "marketing eleitoral" autônomos. (...) O marketing político visa intervir no cenário de representação da política para ativar forças sociais e políticas (simbólicas e materiais, portanto), não somente para atrair eleitores individuais e isolados dentro de uma massa, mas também para mobilizar contingentes 
sociais para uma postura ativa (ou mantê-los na passividade) no processo de disputa política. (Almeida, 2004:18).

As ações de marketing político ou eleitoral, contudo, não são suficientes para explicar o comportamento do eleitor. A forma como a qual os eleitores percebem as mensagens e construções do marketing depende de como o próprio eleitor interage com o meio social que lhe fornece conjuntos de significados que formam suas premissas de consumo (Moorman, 1987).

\section{Relação entre eleitor e voto: como o indivíduo vota?}

Grandi, Marins e Falcão (1992) destacam que determinar o padrão de comportamento dos eleitores e desvendar a maneira como o cidadão pensa e decide seu voto são problemas clássicos da ciência política. Obra pioneira na tentativa de compreender o comportamento do eleitor, The people's choice, de Lazarsfeld, Berelson e Gaudet, de 1948, conclui que o voto do americano é fortemente relacionado ao perfil sociocultural. Desta forma, as características raciais, sociais, religiosas, geográficas influenciam diretamente a intenção de voto do eleitor. Tendências de comportamento eleitoral de um grupo poderiam ser previstas em função da composição das características socioculturais, com base na análise de sua votação histórica, relegando a segundo plano os fatores de curto prazo que poderiam ser influentes na decisão de voto.

Mesmo tendo sido editado há mais de 50 anos, The people's choice ainda continua sendo obra de referência quase obrigatória em qualquer pesquisa sobre o assunto. Da mesma forma, a teoria da escolha racional, de Downs (1957), parece pautar os estudos sobre o comportamento do eleitor. Nela, o voto possui caráter instrumental e parte-se do pressuposto de que o homem político é um ser eminentemente provido de razão, que faz suas escolhas em função da maximização da utilidade e da minimização de prejuízos.

Da mesma forma restritiva, a literatura nacional trata o comportamento do eleitor. Conforme vimos, os estudos normalmente tratam o processo a partir da ideia de racionalidade de um evento eleitoral, em função de pesquisas de comportamento de voto, posicionamento ideológico do cidadão ou preferências partidárias. O comportamento do eleitor é estudado em função das influências externas, como propaganda ou das campanhas. Existe a ideia de um indivíduo que receba as informações políticas e as processe interna e racionalmente para produzir uma resposta, sob a forma de voto.

$\mathrm{Na}$ área de marketing, é muito comum que autores voltados para o mercado gerencial façam afirmativas fortes como "as vinte e duas leis imutáveis do marketing" de Ries e Trout (1994), por exemplo. Pacheco (1993) não foi diferente e apresentou as três leis fundamentais do posicionamento do eleitor: 1) lei da indiferença, segundo a qual há uma redução gradual da indiferença obedecendo cinco fases: indiferença, indefinição, indecisão, simpatia e adesão; 2) lei da procrastinação, segundo a qual a eleição representa um custo para 
o eleitor. Assim, ele adia o máximo possível sua decisão, que ocorreria, na maior parte das vezes, a menos de um mês do pleito; e 3) lei da efemeridade, segundo a qual os interesses e aspirações sociais obedecem a um ciclo de vida determinado e, por isso, os candidatos que forem associados a ideias e aspirações em alta terão maior simpatia dos eleitores e, consequentemente, seus votos.

Em algumas pesquisas, os recursos cognitivos ou a capacidade de análise são confundidos com o grau de escolaridade e, portanto, partir-se-ia do pressuposto de que os eleitores brasileiros não compreendem os assuntos políticos de forma geral e nem seriam capazes de tomar uma decisão racional coerente com seus desejos políticos, em função da baixa escolaridade. Informações do Tribunal Superior Eleitoral (TSE) revelam que dos 106 milhões de eleitores, mais de 70 milhões têm escolaridade abaixo do $1^{\circ}$ grau completo, ou seja, 66,19\% do eleitorado brasileiro receberam pouco ou nenhum ensino. Diante dessa realidade, alguns encaram como improvável que o eleitor brasileiro seja capaz de imprimir alguma racionalidade à sua escolha (Veiga, 1998). Assim, qualquer análise superficial passa pela questão de como a decisão é tomada, já que muitas vezes os temas abordados em campanha são de natureza política complexa, como a reforma da Previdência Social.

Carreirão (2002b) apresenta as diferentes correntes explicativas em pesquisas que têm como objeto o comportamento eleitoral em eleições presidenciais realizadas sob o sistema multipartidário vigente agrupando-as da seguinte forma: voto no "defensor dos interesses do povo"; sofisticação política como determinante do comportamento eleitoral; voto por "identificação ideológica"; voto por avaliação de desempenho; e o "novo eleitor não racional".

A irracionalidade é associada às emoções e vista como a maneira "errada" de fazer uma escolha. A maioria dos estudos nesta área atribui ao personalismo alto poder explicativo quanto ao comportamento político e eleitoral do brasileiro (Aldé, 2001). A principal característica do eleitor brasileiro não seria sua identificação ideológica, mas a emoção; desenvolvendo a descrição de um eleitor intuitivo, a maioria do eleitorado se identificaria, então, com um novo tipo de comportamento eleitoral "não racional", em que elementos afetivos como amizade, imagem e gosto ocupam o lugar das lealdades partidárias ou clientelistas tradicionais. Mesmo nesses casos, o caráter personalista das escolhas estaria presente. Para esta tipologia de eleitor "não racional", portanto, cresce significativamente a importância da mídia na definição de voto (Silveira, 1998; Aldé, 2001). O que corrobora com a visão instrumental do marketing político, que reduz sua atuação à esfera da propaganda política.

A teoria do "novo eleitor não racional" vem do trabalho de Silveira (1998) e apresenta uma extensa tipologia de modalidades de decisão, também a partir do critério de racionalidade. Assim, existiriam três grandes modalidades de comportamento: o não racional tradicional, o novo comportamento não racional e o racional. O autor defende a tese de que há o crescimento de uma nova modalidade de escolha que se define a partir da imagem que os eleitores têm dos candidatos. Essa imagem seria formada a partir das informações fornecidas pela mídia e pelo marketing político por meio de critérios pessoais, como sensibilidade, intuição e gosto. Este eleitor seria incoerente politicamente e volúvel eleitoralmente, teria baixa informação e sua escolha seria eminentemente intuitiva e emocional. Esse tipo seria "produto da 
expansão da importância da mídia eletrônica e do marketing político nos processos eleitorais e do enfraquecimento dos partidos, tudo isso levando a um processo de personalização da política" (Carreirão, 2002a:34).

Normalmente, as ideias de razão e emoção são usadas como antônimos mas, na verdade, não existe estado emocional, exceto as emoções mais básicas, que não leve em consideração os aspectos cognitivos, sociais e culturais.

Segundo Soares (2000), durante a ditadura, uma série de levantamentos revelou uma realidade preocupante: as avaliações das principais questões políticas nacionais, as avaliações dos serviços públicos e das políticas públicas pareciam não ter relação com as preferências partidárias, nem com as intenções de voto. Desses resultados derivava uma conclusão parcial: se o voto não estava ligado ao desempenho governamental, passava a ser desnecessário governar bem:

Os diagnósticos e prognósticos eram sombrios porque sem cobrança não há accountability. Porém, para leigos, sobretudo de direita, esses resultados geraram certezas: o eleitor brasileiro era "irracional" e, se pudesse votar para presidente e governador, escolheria os mandatários a partir de critérios emotivos, irracionais, sendo presa fácil de qualquer demagogo de esquina. Pior, a cabeça do eleitor brasileiro seria um caos: ele não juntaria coisa com coisa. O eleitor seria préideológico e a cultura política brasileira seria pré-cívica. Estas posições elitistas são antigas no Brasil e os dados das pesquisas eleitorais vieram reforçá-las. (Soares, 2000:5)

Seguindo este raciocínio, a pesquisa de Soares ressalta que é importante lembrar que a utilização de critérios não racionais como a emoção ou a empatia não deve ser encarada como prerrogativa de eleitores advindos dos extratos sociais mais baixos. Mesmo entre aqueles que se encontram nas faixas de renda e educação formal mais elevadas, pôde-se verificar baixa associação entre avaliação de políticas públicas e preferência partidária.

De uma forma ou de outra, existe a crença, como vimos, de que a escolha política ou eleitoral é (ou deveria ser, segundo as pesquisas) eminentemente racional e deveria deixar de lado qualquer outro critério que não faça parte da lógica da racionalidade. Assim, as pesquisas não levam em consideração critérios considerados não racionais, como se eles não existissem ou não fossem importantes, ou percebem sua existência como um tipo de entrave a uma escolha "certa" ou "coerente". A questão que agora se apresenta é se é possível delimitar as fronteiras entre razão e emoção no processo de escolha dos eleitores. Podemos duvidar que todas as ações dos indivíduos sejam conscientemente racionais e, por conseguinte, excluam as emoções, os gostos e valores pessoais e sociais (Shott, 1976; Kemper, 1981; Denzin, 1983). Acreditamos ser importante entender como os indivíduos constroem a ideia de votar de uma forma mais ampla, partindo do pressuposto de que as emoções são processos inerentes aos indivíduos e às interações sociais e culturais, sendo, portanto, indissociáveis de sua lógica e racionalidade.

Conforme vimos, pesquisas mostram que o eleitor brasileiro não vota apenas com base em escolhas ideológicas; não é fiel a partidos ou a candidatos; não avalia profundamente as 
questões políticas nacionais ou serviços e políticas públicas mais relevantes. Existiria, então, certo "personalismo" ou "irracionalidade" presente na escolha que não necessariamente podem ser associados apenas aos extratos mais baixos da população, que possuiria menores índices de educação formal.

As emoções podem influenciar as decisões que tomamos, assim como o resultado de nossas decisões pode influenciar as emoções que experimentamos (Schwarz, 2000). Assim, dentro da disciplina do comportamento do consumidor existem várias pesquisas sobre a formação de atitudes, processo de decisão e intenção e comportamento que poderiam ser aplicados na pesquisa do comportamento do eleitor (Chaudhuri, 2002; Crespi, 2001; Foxall, 2001; Olshavsky e Granbois, 1991; Schwarz, 2000; Zajonc e Markus, 1991).

Entre a atitude com relação a um candidato, a decisão por um deles, a intenção de voto e o comportamento real — o ato efetivo de votar em um determinado candidato - , o eleitor percorre um longo caminho onde são avaliados riscos e benefícios presentes e futuros envolvidos na escolha. Se os indivíduos levam em consideração também outros aspectos que não aqueles socialmente aceitos e tidos como racionais e lógicos, qual o papel que as emoções e as influências pessoais desempenham nesse processo?

Vimos que a nova orientação de marketing entende consumo como atribuição de significados e que o consumo é também uma forma de expressão. Então, o consumo político é a expressão do comportamento do eleitor. Dermody e Scullion (2001) acrescentam que o consumo pode tomar várias formas e os indivíduos podem construir sua própria forma pessoal. Assim, cada cidadão pode construir, diferentemente dos demais, sua relação com o voto. Corroborando esta ideia, Bannon (2003) atribui ao ato de votar dupla função: como um processo e como evento, acrescentando que existe uma relação entre o processo e cada indivíduo membro do sistema eleitoral. Neste sentido, a expansão da mídia corroborou para a personalização de participação popular na política, já que democratizou o acesso à informação político-eleitoral. Este autor já apresenta uma abordagem diferente e se propõe a analisar o comportamento de voto de duas perspectivas: da ciência política e do comportamento de compra do consumidor. Embora não fique muito claro como os modelos importados do comportamento do consumidor tenham sido usados, já demonstra a procura por diferentes fontes para obter maior compreensão do comportamento do eleitor.

Balbachevsky e Holzhacker (2004) apresentam a hipótese de que o voto pode ser compreendido como uma ação social. Os eleitores têm diferentes motivações, que obedecem um padrão de comportamento definido. O voto é compreendido como estratégia do indivíduo para expressar sua identidade com o candidato, sua oposição ou sua crença no poder de realização de objetivos do político.

\section{Conclusões e pesquisas futuras}

Neste trabalho procuramos mostrar que o comportamento do eleitor ainda é muito pouco estudado. Mesmo com a contribuição de diferentes áreas do conhecimento, a produção bra- 
sileira sobre as escolhas político-eleitorais ainda é muito pequena. Embora seja um tema de crucial interesse para a administração pública, as maiores contribuições para o estudo do eleitor e de seu processo de escolha vêm das ciências sociais e políticas.

Os poucos estudos publicados na área da administração encontram-se sob a égide do marketing político e são coerentes com a orientação gerencial dos estudos de marketing. A perspectiva tradicional desses estudos é consistente com a orientação gerencial do marketing para produtos e parte da premissa de que o eleitor ocupa uma posição de "subracionalidade". Ele é conhecido, homogêneo e manipulável. O eleitor não tem memória das decisões passadas, não tem satisfação plena com os resultados do processo eleitoral, nem acredita na possibilidade de satisfação. Assim, as campanhas políticas teriam grande poder de persuasão sobre os eleitores e poderiam determinar em grande parte a escolha político-eleitoral.

Se o candidato é encarado como um produto, seria possível mudar a "embalagem" e o conteúdo para reposicioná-lo. Entendemos que esses pressupostos não só diminuem a importância política do processo, como também subestimam as capacidades tanto do eleitor, quanto do político, e superestimam a importância da propaganda política. Permanece pouco explorado o processo de formação de preferências do eleitor, baseado principalmente nos componentes racionais e emocionais.

Este artigo representa um primeiro esforço no sentido de compreender melhor as escolhas político-eleitorais. Para tanto, realizamos um levantamento inicial do que vem sendo produzido sobre o tema do comportamento do eleitor em diferentes áreas. As diversas representações do eleitor parecem apontar para um mesmo horizonte. Ao evidenciar que podem existir outros olhares sobre o assunto além da influência de fatores externos no comportamento, acreditamos que também seja importante questionar a afirmação de que uma escolha deva excluir as emoções para ser a "certa". Este julgamento de valor é antagônico à perspectiva de alguns pesquisadores (Zajonc,1980) de que não é possível separar a razão da emoção durante o processo de construção de preferências.

Em virtude da restrita produção acadêmica sobre comportamento do eleitor e marketing político na administração pública, acreditamos que a sistematização do conhecimento produzido na área possa ser capaz de mostrar um amplo campo de possibilidades para futuros estudos críticos, teóricos e empíricos. Pensamos que a área tem muito a oferecer para o aprofundamento da compreensão do comportamento político-eleitoral dos cidadãos. A pluralidade de visões só poderá trazer benefícios para o entendimento maior do tema.

Assim, é necessário pensar em uma agenda de pesquisa que contemple o estudo do comportamento do eleitor; processo decisório do eleitor; formação de preferências — atitude com relação a candidatos; fatores que influenciam as atitudes e a decisão do indivíduo (grupos de referência, pressões do tempo, discursos dos candidatos, propostas político-eleitorais, líderes de opinião, publicação de pesquisas de opinião, mídia etc.). 


\section{Referências}

ALDÉ, Alessandra. A construção da política: cidadão comum, mídia e atitude política. Tese (doutorado) - Instituto Universitário de Pesquisas do Rio de Janeiro, Rio de Janeiro, 2001.

ALMEIDA, Antônio J.F.S. de. Evolução de imagem e marketing nos 18 meses de governo Lula. In: ENCONTRO NACIONAL DA ANPOCS, XVIII, Caxambu, 2004.

ALMEIDA, Carlos A.; YOUNG, Clifford. As bases ideológicas do comportamento eleitoral. In: ENCONTRO NACIONAL DA ABCP — ASSOCIAÇÃO BRASILEIRA DE CIÊNCIA POLÍTICA, 3ํ, Niterói, 2002.

BAINES, Paul R.; EGAN, John. Marketing and political campaigning: mutually exclusive or exclusively mutual? Qualitative Market Research, v. 4, n. 1, p. 25-34, 2001.

BALBACHEVSKY, Elizabeth; HOLZHACKER, Denilde Oliveira. Identidade, oposição e pragmatismo: o conteúdo estratégico da decisão eleitoral em 13 anos de eleições. Opinião Pública, v. X, n. 2, p. 242-253, out. 2004.

BANNON, Declan P. Voting, non-voting and consumer buying behaviour: non-voter segmentation (NVS) and the underlining causes of electoral inactivity. Journal of Public Affairs, v. 3, n. 2, p. 138151, 2003.

CARREIRÃO, Yan de S. A decisão de voto nas eleições presidenciais brasileiras. Rio de Janeiro: FGV, 2002a.

CARREIRÃO, Yan de S. Identificação ideológica e voto para presidente. Opinião Pública, v. VIII, n. 1, p. 54-79, 2002b.

CHAUDHURI, Arjun. A study of emotion and reason in products and services. Journal of Consumer Behaviour, v. 1, n. 3, p. 267-279, 2002.

CRESPI, Irving. What kinds of attitude measure are predictive of behaviour? Public Opinion Quarterly, v. 35, n. 3, p. 327-334, 2001.

DEAN, Dianne; CROFT, Robin. Friends and relations: long-term approaches to political campaigning. European Journal of Marketing, v. 35, n. 11/12, p. 1197-1216, 2001.

DENZIN, Norman K. A note on emotionality, self and interaction. The American Journal of Sociology, v. 89, p. 402-409, 1983.

DERMODY, Janine; SCULLION, Richard. Desilusions of grandeur? Marketing's contribution to "meaningful" western political consumption. European Journal of Marketing, v. 35, n. 9/10, p. 1085-1098, 2001.

DOWNS, Anthony. An economic theory of democracy. New York: Harpers \& Row, 1957.

EAGLY, Alice H.; CHAIKEN, Shelly. The psychology of attitudes. Orlando, FL: Harcourt Brace, 1993. 
FOXALL, Gordon R. Foundations of consumer behaviour analysis. Marketing Theory, v. 1, n. 2, p. 165-199, 2001.

GRANDI, Rodolfo; MARINS, Alexandre; FALCÃO, Eduardo (Org.). Voto é marketing... o resto é política. São Paulo: Edições Loyola, 1992.

HOLBROOK. Morris B.; O'SHAUGHNESSY, John. The role of emotion in advertising. Psychology and Marketing, v. 1, p. 45-64, 1984.

KEMPER, Theodore D. Social constructivist and positivist approaches to the sociology of emotions. American Journal of Sociology, v. 87, p. 336-362, 1981.

KOTLER, Phillip. Overview of political candidate marketing. Advances in Consumer Research, v. 2, n. 1, p. 761-769, 1975.

LAZARSFELD, Paul F.; BERELSON, Bernard; GAUDET, Hazel. The people's choice: how the voter makes up his mind in a presidential campaign. 6. ed. New York: Columbia University Press, 1965.

LAZARUS, R.S. Thoughts on the relations between emotion and cognition. American Psychologist, v. 37, p. 1019-1024, 1982.

LOCK, Andrew; HARRIS, Phil. Political marketing — vive la difference! European Journal of Marketing, v. 30, n. 10/11, p. 14-24, 1996.

MARLAND, Alex. Marketing political soap: a political marketing view of selling candidates like soap, of electioneering as a ritual, and of electoral military analogies. Journal of Public Affairs, v. 3, n. 2, p. 103-115, 2003.

MOORMAN, Christine. Marketing as technique: the influence of marketing on the meanings of consumption. In: FIRAT, Ali F.; DHOLAKIA, Nikhilesh.; BAGOZZI, Richard P. Philosophical and radical thought in marketing. Massachusetts: Lexington, 1987.

NIFFENEGGER, P. Strategies for success from political marketers. Journal of Consumer Marketing, v. 6, n. 1, p. 45-51, 1989.

O'SHAUGNNESSY, Nicholas. The marketing of political marketing. European Journal of Marketing, v. 35, n. 9/10, p. 1047-1057, 2001.

OLSHAVSKY, Richard W.; GRANBOIS, Donald H. Consumer decision-making - fact or fiction? In: KASSARJIAN, Harold H.; ROBERTSON, Thomas S. (Ed.). Perspectives in consumer behaviour. Englewood Cliffs, NJ: Prentice Hall, 1991.

PACHECO, Cid. Marketing político versus marketing eleitoral. In: PACHECO, Cid. Voto é marketing? Rio de Janeiro: UFRJ-ECO, 1993.

PRAÇA, Sergio. Informação e responsabilidade eleitoral. Comunicação, Mídia \& Consumo, v. 2, n. 3, p. 87-108, 2005.

QUEIROZ, Adolpho. Voto, mídia e pesquisa: propaganda política no Brasil. Comunicação \& Sociedade, n. 30, p. 105-140, 1998. 
RIES, Al; TROUT, Jack. The 22 immutable laws of marketing. New York: Harper Collins, 1994.

SCHWARZ, Norbert. Emotion, cognition and decision making. Cognition and Emotion, v. 14, n. 4, p. 433-440, 2000.

SHAMA, Avraham. Aplications of marketing concepts to candidate marketing. Advances in Consumer Research, v. 2, n. 1, p. 793-801, 1975.

SHOTT, Susan. Emotion and social life: a symbolic interactionist analysis. The American Journal of Sociology, v. 84, n. 6, p. 1317-1334, maio 1976.

SILVEIRA, Flavio E. A decisão do voto no Brasil. Porto Alegre: EDIPUCRS, 1998.

SOARES, Gláucio A. D. Em busca da racionalidade perdida: alguns determinantes do voto no Distrito Federal. Revista Brasileira de Ciências Sociais, v. 15, n. 43, p. 5-23, jun. 2000.

UNIVERSIDADE FEDERAL DO RIO DE JANEIRO. Escola de Comunicação. Central de Produção Multimídia. Voto é marketing? Rio de Janeiro: UFRJ-ECO, 1993.

VEIGA, Luciana F. O horário eleitoral, o eleitor e a formação da preferência. Comunicação \& Política, nova série, v. V, n. 3, set./dez. 1998.

WRING, Dominic. Reconciling marketing with political science: theories of political marketing. Journal of Marketing Management, v. 13, p. 651-663, 1997.

ZAJONC, R.B. Feeling and thinking: preferences need no inferences. American Psychologist, v. 35, p. 151-175, 1980.

ZAJONC, Robert B.; MARKUS, Hazel. Affective and cognitive factors in preferences. In: KASSARJIAN, Harold H.; ROBERTSON, Thomas S. (Ed.). Perspectives in consumer behaviour. Englewood Cliffs, NJ: Prentice Hall, 1991.

Denise Franca Barros é professora da Escola Brasileira de Administração Pública e de Empresas (Ebape/ FGV-RJ). E-mail: denise.barros@fgv.br.

João Felipe Rammelt Sauerbronn é professor da FGV Direito Rio. E-mail: joao.sauerbronn@fgv.br.

Eduardo André Teixeira Ayrosa é professor da Ebape/FGV-RJ. E-mail: eduardo.ayrosa@fgv.br. 
